\title{
Nasal Cream Dosage Form
}

National Cancer Institute

\section{Source}

National Cancer Institute. Nasal Cream Dosage Form. NCI Thesaurus. Code C91151.

A cream intended for administration to the mucosa of the nose. 